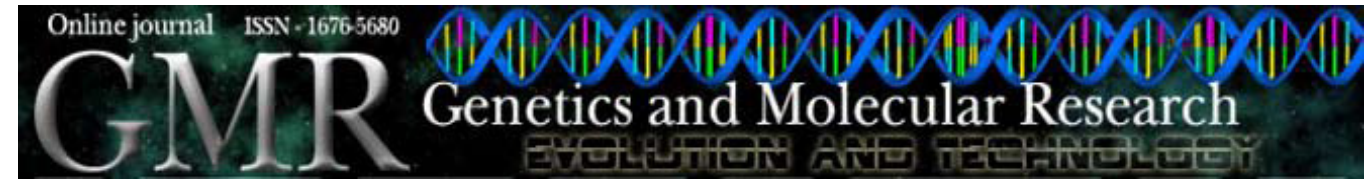

\title{
Genotoxicity and mutagenicity of Rosmarinus officinalis (Labiatae) essential oil in mammalian cells in vivo
}

\author{
E.L. Maistro ${ }^{1}$, S.F. Mota ${ }^{2}$, E.B. Lima ${ }^{2}$, B.M. Bernardes ${ }^{2}$ and \\ F.C. Goulart ${ }^{1}$ \\ ${ }^{1}$ Departamento de Fonoaudiologia, Faculdade de Filosofia e Ciências, \\ Universidade Estadual Paulista, Marília, SP, Brasil \\ ${ }^{2}$ Faculdade de Farmácia e Biomedicina, \\ Universidade José do Rosário Vellano (UNIFENAS), Alfenas, \\ MG, Brasil \\ Corresponding author: E.L. Maistro \\ E-mail: edson.maistro@marilia.unesp.br
}

Genet. Mol. Res. 9 (4): 2113-2122 (2010)

Received March 19, 2010

Accepted July 27, 2010

Published October 26, 2010

DOI 10.4238/vol9-4gmr857

\begin{abstract}
Rosmarinus officinalis (rosemary) oil is widely used by the cosmetic, food, and pharmaceutical industries as a fragrance component of soaps, creams, lotions, and perfumes. Although it is popular, potential harmful side-effects of the oil have been described. We investigated the genotoxic and mutagenic potential of essential oil of $R$. officinalis in rodents, using comet, micronucleus and chromosome aberration assays. The animals were treated by gavage with one of three dosages of rosemary oil $(300,1000$ or $2000 \mathrm{mg} / \mathrm{kg})$. Liver and peripheral blood cells were collected from Swiss mice $24 \mathrm{~h}$ after treatment for the comet assay (genotoxicity endpoint), along with bone marrow cells for the micronucleus test (mutagenicity endpoint). Bone marrow cells were collected from Wistar rats $24 \mathrm{~h}$ after oil treatment for the micronucleus and chromosome aberration assays. Based on the comet assay, all three doses of rosemary oil induced significant
\end{abstract}


increases in DNA damage in the mouse cells. There was a significant increase in micronucleated cells and chromosome aberrations only at the two higher doses. We conclude that rosemary essential oil provokes genotoxic and mutagenic effects when administered orally.

Key words: Chromosome aberrations; Comet assay; Essential oil; Micronucleus test; Rosmarinus officinalis

\section{INTRODUCTION}

Rosemary (Rosmarinus officinalis (Labiatae)) originally cames from southern Europe (Héthelyi et al., 1987). Its leaves and oil are commonly used as spice and flavoring agents in food processing because of its desirable flavor, antimicrobial and antioxidant activity, due to phenolic diterpenes, such as rosmarinic acid and carnosol (Collins and Charles, 1987; Baratta et al., 1998; Mangena and Muyima, 1999; al-Sereiti et al., 1999; Larràn et al., 2001). This oil is widely used by the cosmetic, food, and pharmaceutical industries as a fragrance component of soaps, creams, lotions, and perfumes. The leaves are used in the preparation of alcoholic beverages (vermouth), herbal soft drinks, and cooked foods and sauces. In medicine it is used as a stimulant of blood circulation, the heart, and the nervous system, probably because of its camphor content. It is applied topically to treat articulation, muscular, rheumatic, and traumatic pains; it is also employed in lotions against baldness (Aqel, 1991; Newal et al., 1996; al-Sereiti et al., 1999). However, potential harmful side effects of rosemary oil have been described. Lemonica et al. (1996) reported anti-implantation effect of it and the aqueous extract of rosemary leaves in Wistar rats. Rosemary oil, taken orally, can trigger convulsions; epileptic patients should exercise caution in using this oil, and should never ingest quantities larger than those used in foods, especially during pregnancy. Topical preparations containing rosemary oil are potentially harmful to hypersensitive people who may be allergic to camphor (Lemonica et al., 1996; Newal et al., 1996; Burkhard et al., 1999).

Considering the high consumption of essential oil of rosemary, the reports of some harmful side-effects, and the lack of in vivo genotoxic and mutagenic evaluations of this oil, we examined the genotoxic/mutagenic potential of acute administration of rosemary oil in rodent cells, using comet, micronucleus and chromosome aberration assays.

\section{MATERIAL AND METHODS}

\section{Plant material}

Plant material was obtained from Santos Flora Ltda. (Ervas Medicinais e Aromáticas) located in São Paulo, SP, Brazil: this material had been imported from Turkey, with botanical identification as $R$. officinalis. A voucher specimen was deposited in the "Laboratório de Fitofármacos" of UNIFENAS, Alfenas, MG, Brazil. The oil was obtained by hydrodistillation for $2 \mathrm{~h}$ in a Clevenger-like apparatus of dried crushed aerial parts. Rosemary essential oil was recovered directly, using a micropipet from the upper part of the distillate, without adding any solvent, and was stored in clean brown glass bottles at $4^{\circ} \mathrm{C}$. 


\section{Chemicals}

The alkylating agent cyclophosphamide (CPA, CAS No. C 0768, Sigma) was used as the DNA damaging agent in comet, micronucleus and chromosome aberration assays.

\section{Animals and assay procedures}

Experiments were carried out using 12-week-old albino Swiss mice weighing 25-30 $\mathrm{g}$ and 6-week-old Wistar rats, weighing approximately $100 \mathrm{~g}$. The animals were acquired from the animal house of the José do Rosário Vellano University (UNIFENAS), and kept in polyethylene boxes, in a climate-controlled environment $\left(25 \pm 4^{\circ} \mathrm{C}, 55 \pm 5 \%\right.$ humidity $)$ with a 12-h light/dark cycle (7:00 am to 7:00 pm). Food (Labina - Purina) and water were available ad libitum. The mice and rats were divided into experimental groups of six animals each ( 3 females and 3 males). Rosemary essential oil was administered at a single dose of $0.5 \mathrm{~mL}$ by gavage, at concentrations of 300,1000 or $2000 \mathrm{mg} / \mathrm{kg}$ body weight, selected on the basis of acute toxicity studies in mice and $\mathrm{ED}_{50}$ based on anti-inflammatory and analgesic activity analysis (Faria, 2005). The negative control groups (both mice and rats) received distilled water. The positive control groups received $50 \mathrm{mg}$ cyclophosphamide $/ \mathrm{kg}$. The Animal Bioethics Committee of UNIFENAS approved this study.

\section{Comet assay}

The alkaline comet assay was carried out using the method described by Speit and Hartmann (1999) based on the original work of Singh et al. (1988) and includes modifications introduced by Klaude et al. (1996) as well as some modifications. Briefly, liver and peripheral blood cells were collected $24 \mathrm{~h}$ post-gavage. An aliquot of these cells was removed to determine cell viability. Cell counting was performed using a hemocytometer. Cell viability was determined by Trypan blue dye exclusion. The number of Trypan blue-negative cells was considered the number of viable cells; it was superior to $93 \%$. A $10-\mu \mathrm{L}$ aliquot was mixed with $120 \mu \mathrm{L}$ $0.5 \%(\mathrm{w} / \mathrm{v})$ low-melting point agarose at $37^{\circ} \mathrm{C}$ and rapidly spread on a microscope slide precoated with $1.5 \%(\mathrm{w} / \mathrm{v})$ normal-melting point agarose. Coverslips were added and the slides were allowed to gel at $4^{\circ} \mathrm{C}$, for $20 \mathrm{~min}$, before gently removing the coverslips and immersing the slides in cold freshly prepared lysing solution consisting of $89 \mathrm{~mL}$ of a stock solution $(890$ $\mathrm{mL}$ distilled water containing $2.5 \mathrm{M} \mathrm{NaCl}, 100 \mathrm{mM}$ EDTA, $10 \mathrm{mM}$ Tris and $1 \%$ (w/v) sodium lauryl sarcosine with the $\mathrm{pH}$ set to 10.0 by the addition of about $8 \mathrm{~g}$ solid $\mathrm{NaOH}$ ) plus $1 \mathrm{~mL}$ Triton X-100 and $10 \mathrm{~mL}$ DMSO. After treatment, the slides were stored at $4^{\circ} \mathrm{C}$ for $1 \mathrm{~h}$, protected from light and then placed at the anode of a gel electrophoresis box containing high $\mathrm{pH}(>13)$ electrophoresis buffer $(300 \mathrm{mM} \mathrm{NaOH}$ per $1 \mathrm{mM}$ EDTA, prepared from a stock solution of 10 $\mathrm{N} \mathrm{NaOH}$ and $200 \mathrm{mM}$ EDTA, $\mathrm{pH} \mathrm{10}$ ) at $4^{\circ} \mathrm{C}$ for $20 \mathrm{~min}$ before electrophoresis to allow the DNA to unwind. Electrophoresis was run at $25 \mathrm{~V}$ and $300 \mathrm{~mA}$ for $20 \mathrm{~min}$ at $4^{\circ} \mathrm{C}$ in an ice bath, after which the slides were submerged in neutralization buffer $(0.4 \mathrm{M}$ Tris-HCl, $\mathrm{pH} 7.5)$ for 15 min, dried at room temperature and fixed in $100 \%$ ethyl alcohol for $10 \mathrm{~min}$. The slides were dried and stored at least overnight before staining by covering the preparation with $30 \mu \mathrm{L} 1 \mathrm{X}$ ethidium bromide staining solution (prepared from a 10X stock solution containing $200 \mu \mathrm{g} / \mathrm{mL}$ ethidium bromide) and then covered with a coverslip. The material was evaluated immediately 
at a 400X magnification using an Olympus BX50 fluorescence microscope with a 515- to 560$\mathrm{nm}$ excitation filter and a $590-\mathrm{nm}$ barrier filter.

The extent and distribution of DNA damage indicated by the comet assay was evaluated by examining at least 100 randomly selected and non-overlapping cells on the slides. The cells were visually scored, according to tail size, into four classes: 1) class 0 , undamaged and with no tail; 2) class 1, tail shorter than the diameter of the head (nucleus); 3) class 2 , tail length one to two times the head diameter, and 4) class 3 , tail longer than twice the head diameter. Comets with no heads and images with nearly all DNA in the tail, or with a very wide tail, were excluded from evaluation because they probably represent dead cells (Hartmann and Speit, 1997). The total score for 100 comets was obtained by multiplying the number of cells in each class by the damage class, ranging from 0 (all undamaged) to 300 (all maximally damaged).

\section{Micronucleus and chromosome aberration assays}

The rats were injected intraperitoneally with $0.5 \mathrm{~mL} 0.16 \%$ colchicines, $90 \mathrm{~min}$ prior to euthanasia, $24 \mathrm{~h}$ after the oil treatments. Both femur bones were excised and the bone marrow flushed into test tubes, using a syringe. For the micronucleus assay in both mice and rats, the assay was carried out following standard protocols, as recommended by Schmid (1975) and Krishna and Hayashi (2000). The bone marrow from both femurs was flushed out using $2 \mathrm{~mL}$ saline $(0.9 \% \mathrm{NaCl})$ and centrifuged for $7 \mathrm{~min}$. The supernatant was discarded and spread smears made. The slides were coded for "blind" analysis, fixed with methanol and stained with Giemsa solution. For analysis of the micronucleated cells, 2000 polychromatic erythrocytes per animal were scored to determine the mutagenic property of the extract. To detect possible cytotoxic effects, the poychromatic erythrocyte/normochromatic erythrocyte ratio in 200 erythrocytes/mouse was calculated (Gollapudi and McFadden, 1995). The cells were blindly scored under a light microscope at a 1000X magnification. The mean number of micronucleated polychromatic erythrocytes in individual mouse and rat was used as the experimental unit, with variability (standard deviation) calculated from differences among animals within the same group.

Bone marrow preparations from the other femur from Wistar rats were used for analysis of chromosome aberrations in metaphase cells, using the technique of Preston et al. (1987). One hundred metaphases per animal (600 metaphases per group) were analyzed, in order to determine the number of chromosomal aberrations, in a blind test. The chromosomal aberrations were classified according to Savage (1976) as gaps, breaks, deletions, fragments, rings, and dicentric chromosomes. Since the cytogenetic significance of gaps is still not well established, statistical analyses were carried out excluding gaps. The mitotic index was obtained by counting the number of mitotic cells in 1000 cells per animal.

\section{Statistical analysis}

The comet, micronucleus and chromosome aberration assay data were submitted to one-way analysis of variance (ANOVA) and the Tukey-Kramer multiple comparison test (Sokal and Rohlf, 1995), using the GraphPad Instat ${ }^{\mathbb{B}}$ program version 3.01. The results were con- 
sidered to be statistically significant at $\mathrm{P}<0.05$.

\section{RESULTS}

Our comet assay results are shown in Tables 1 and 2, where the female and male results for the different concentrations of oil and the cyclophosphamide-positive control are compared with the negative control (water). As expected, when the positive control was compared to the negative control, we found that cyclophosphamide induced a significant increase $(\mathrm{P}<0.001$ or greater) in comet assay DNA migration for mouse liver and leukocyte cells (Tables 1,2). We found a significant increase in DNA migration at all three doses of rosemary oil in both liver cells and leukocytes. At oil doses that induced a significant increase in DNA damage, most of the damaged cells showed minor damage (class 1), very few had a large amount of damage (classes 2 and 3).

Table 1. DNA migration in the comet assay for the assessment of genotoxicity of Rosmarinus officinalis essential oil in liver cells of female (F) and male (M) Swiss mice in vivo.

\begin{tabular}{|c|c|c|c|c|c|c|c|}
\hline \multirow[t]{2}{*}{ Treatments } & \multirow[t]{2}{*}{ Animals } & \multirow[t]{2}{*}{ Total $^{1}$} & \multicolumn{4}{|c|}{ Comet class } & \multirow[t]{2}{*}{ Scores } \\
\hline & & & 0 & 1 & 2 & 3 & \\
\hline Control & $\begin{array}{c}\mathrm{F}_{1} \\
\mathrm{~F}_{2} \\
\mathrm{~F}_{3} \\
\mathrm{M}_{1} \\
\mathrm{M}_{2} \\
\mathrm{M}_{3} \\
\text { Mean } \pm \mathrm{SD} \\
\end{array}$ & $\begin{array}{c}5 \\
1 \\
2 \\
4 \\
3 \\
5 \\
3.33 \pm 1.6 \\
\end{array}$ & $\begin{array}{l}95 \\
99 \\
98 \\
96 \\
97 \\
95\end{array}$ & $\begin{array}{l}5 \\
1 \\
2 \\
4 \\
3 \\
5\end{array}$ & $\begin{array}{l}0 \\
0 \\
0 \\
0 \\
0 \\
0\end{array}$ & $\begin{array}{l}0 \\
0 \\
0 \\
0 \\
0 \\
0\end{array}$ & $\begin{array}{c}5 \\
1 \\
2 \\
4 \\
3 \\
5 \\
3.33 \pm 1.6 \\
\end{array}$ \\
\hline $\begin{array}{l}\text { R. officinalis oil } \\
(300 \mathrm{mg} / \mathrm{kg})\end{array}$ & $\begin{array}{c}\mathrm{F}_{1} \\
\mathrm{~F}_{2} \\
\mathrm{~F}_{3} \\
\mathrm{M}_{1} \\
\mathrm{M}_{2} \\
\mathrm{M}_{3} \\
\text { Mean } \pm \mathrm{SD}\end{array}$ & $\begin{array}{c}13 \\
9 \\
15 \\
22 \\
18 \\
20 \\
16.16 \pm 4.7^{* *}\end{array}$ & $\begin{array}{l}87 \\
91 \\
85 \\
78 \\
82 \\
80\end{array}$ & $\begin{array}{r}11 \\
8 \\
15 \\
20 \\
15 \\
15\end{array}$ & $\begin{array}{l}2 \\
1 \\
0 \\
2 \\
3 \\
5\end{array}$ & $\begin{array}{l}0 \\
0 \\
0 \\
0 \\
0 \\
0\end{array}$ & $\begin{array}{c}15 \\
10 \\
15 \\
24 \\
21 \\
21 \\
17.66 \pm 5.2 *\end{array}$ \\
\hline $\begin{array}{l}\text { R. officinalis oil } \\
(1000 \mathrm{mg} / \mathrm{kg})\end{array}$ & $\begin{array}{c}\mathrm{F}_{1} \\
\mathrm{~F}_{2} \\
\mathrm{~F}_{3} \\
\mathrm{M}_{1} \\
\mathrm{M}_{2} \\
\mathrm{M}_{3} \\
\text { Mean } \pm \mathrm{SD}\end{array}$ & $\begin{array}{c}27 \\
17 \\
16 \\
17 \\
17 \\
15 \\
18.16 \pm 4.4^{* *} \\
\end{array}$ & $\begin{array}{l}73 \\
83 \\
84 \\
83 \\
83 \\
85\end{array}$ & $\begin{array}{l}24 \\
17 \\
13 \\
15 \\
15 \\
13\end{array}$ & $\begin{array}{l}3 \\
0 \\
3 \\
2 \\
2 \\
2\end{array}$ & $\begin{array}{l}0 \\
0 \\
0 \\
0 \\
0 \\
0\end{array}$ & $\begin{array}{r}30 \\
17 \\
19 \\
19 \\
19 \\
17 \\
20.16 \pm 4.9^{*} \\
\end{array}$ \\
\hline $\begin{array}{l}\text { R. officinalis oil } \\
(2000 \mathrm{mg} / \mathrm{kg})\end{array}$ & $\begin{array}{c}\mathrm{F}_{1} \\
\mathrm{~F}_{2} \\
\mathrm{~F}_{3} \\
\mathrm{M}_{1} \\
\mathrm{M}_{2} \\
\mathrm{M}_{3} \\
\text { Mean } \pm \mathrm{SD}\end{array}$ & $\begin{array}{c}16 \\
20 \\
20 \\
15 \\
11 \\
15 \\
16.16 \pm 3.4^{* *}\end{array}$ & $\begin{array}{l}84 \\
80 \\
80 \\
85 \\
89 \\
85\end{array}$ & $\begin{array}{l}15 \\
18 \\
18 \\
15 \\
10 \\
15\end{array}$ & $\begin{array}{l}1 \\
2 \\
2 \\
0 \\
1 \\
0\end{array}$ & $\begin{array}{l}0 \\
0 \\
0 \\
0 \\
0 \\
0\end{array}$ & $\begin{array}{c}17 \\
22 \\
22 \\
15 \\
12 \\
15 \\
17.16 \pm 4.0^{*}\end{array}$ \\
\hline $\begin{array}{l}\text { Cyclophosphamide } \\
(50 \mathrm{mg} / \mathrm{kg})\end{array}$ & $\begin{array}{c}\mathrm{F}_{1} \\
\mathrm{~F}_{2} \\
\mathrm{~F}_{3} \\
\mathrm{M}_{1} \\
\mathrm{M}_{2} \\
\mathrm{M}_{3} \\
\mathrm{Mean} \pm \mathrm{SD} \\
\end{array}$ & $\begin{array}{c}45 \\
35 \\
33 \\
34 \\
26 \\
45 \\
36.33 \pm 7.4^{* *} \\
\end{array}$ & $\begin{array}{l}55 \\
65 \\
68 \\
66 \\
74 \\
55\end{array}$ & $\begin{array}{l}25 \\
24 \\
25 \\
32 \\
15 \\
25\end{array}$ & $\begin{array}{r}10 \\
6 \\
5 \\
2 \\
8 \\
15\end{array}$ & $\begin{array}{r}10 \\
5 \\
3 \\
0 \\
3 \\
5\end{array}$ & $\begin{array}{r}75 \\
51 \\
44 \\
36 \\
40 \\
70 \\
52.66 \pm 16.2^{* *} \\
\end{array}$ \\
\hline
\end{tabular}

*Significantly different from the negative control $(\mathrm{P}<0.05)$. * Significantly different from the negative control $(\mathrm{P}$ $<0.001)$. ${ }^{1}$ Total number of damaged cells (classes $1+2+3$ ). 
Table 2. DNA migration in the comet assay for the assessment of genotoxicity of Rosmarinus officinalis essential oil in peripheral blood cells from Swiss mice female (F) and male (M) in vivo.

\begin{tabular}{|c|c|c|c|c|c|c|c|}
\hline \multirow[t]{2}{*}{ Treatments } & \multirow[t]{2}{*}{ Animals } & \multirow[t]{2}{*}{ Total $^{1}$} & \multicolumn{4}{|c|}{ Comet class } & \multirow[t]{2}{*}{ Scores } \\
\hline & & & 0 & 1 & 2 & 3 & \\
\hline Control & $\begin{array}{c}\mathrm{F}_{1} \\
\mathrm{~F}_{2} \\
\mathrm{~F}_{3} \\
\mathrm{M}_{1} \\
\mathrm{M}_{2} \\
\mathrm{M}_{3} \mathrm{SD} \\
\text { Mean }{ }^{ \pm} \mathrm{SD}\end{array}$ & $\begin{array}{c}2 \\
2 \\
2 \\
3 \\
5 \\
2 \\
2.66 \pm 1.2 \\
\end{array}$ & $\begin{array}{l}98 \\
98 \\
98 \\
97 \\
95 \\
98\end{array}$ & $\begin{array}{l}2 \\
2 \\
1 \\
2 \\
3 \\
2\end{array}$ & $\begin{array}{l}0 \\
0 \\
1 \\
1 \\
2 \\
0\end{array}$ & $\begin{array}{l}0 \\
0 \\
0 \\
0 \\
0 \\
0\end{array}$ & $\begin{array}{c}2 \\
2 \\
3 \\
4 \\
7 \\
2 \\
3.33 \pm 1.9 \\
\end{array}$ \\
\hline $\begin{array}{l}\text { R. officinalis oil } \\
(300 \mathrm{mg} / \mathrm{kg})\end{array}$ & 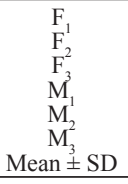 & $\begin{array}{r}10 \\
9 \\
31 \\
7 \\
30 \\
10 \\
16.16 \pm 11.1^{*} \\
\end{array}$ & $\begin{array}{l}90 \\
91 \\
69 \\
93 \\
70 \\
90\end{array}$ & $\begin{array}{r}9 \\
9 \\
28 \\
4 \\
24 \\
4\end{array}$ & $\begin{array}{l}1 \\
0 \\
3 \\
2 \\
5 \\
5\end{array}$ & $\begin{array}{l}0 \\
0 \\
0 \\
1 \\
1 \\
1\end{array}$ & $\begin{array}{c}11 \\
9 \\
34 \\
11 \\
37 \\
17 \\
19.8 \pm 12.4^{*} \\
\end{array}$ \\
\hline $\begin{array}{l}\text { R. officinalis oil } \\
(1000 \mathrm{mg} / \mathrm{kg})\end{array}$ & $\begin{array}{c}\mathrm{F}_{1} \\
\mathrm{~F}_{2} \\
\mathrm{~F}_{3} \\
\mathrm{M}_{1} \\
\mathrm{M}_{2} \\
\mathrm{M}_{3}^{2} \mathrm{SD} \\
\mathrm{Mean} \pm \mathrm{SD}\end{array}$ & $\begin{array}{r}20 \\
14 \\
22 \\
18 \\
17 \\
9 \\
16.66 \pm 4.6^{*} \\
\end{array}$ & $\begin{array}{l}80 \\
86 \\
78 \\
82 \\
83 \\
91\end{array}$ & $\begin{array}{l}13 \\
10 \\
18 \\
17 \\
13 \\
17\end{array}$ & $\begin{array}{l}7 \\
4 \\
4 \\
1 \\
4 \\
1\end{array}$ & $\begin{array}{l}0 \\
0 \\
0 \\
0 \\
0 \\
1\end{array}$ & $\begin{array}{c}27 \\
18 \\
26 \\
19 \\
21 \\
22 \\
22.1 \pm 3.6^{* *} \\
\end{array}$ \\
\hline $\begin{array}{l}\text { R. officinalis oil } \\
(2000 \mathrm{mg} / \mathrm{kg})\end{array}$ & $\begin{array}{c}\mathrm{F}_{1} \\
\mathrm{~F}_{2} \\
\mathrm{~F}_{3} \\
\mathrm{M}_{1} \\
\mathrm{M}_{2} \\
\mathrm{M}_{3} \\
\mathrm{Mean} \pm \mathrm{SD} \\
\end{array}$ & $\begin{array}{r}25 \\
26 \\
33 \\
31 \\
31 \\
18 \\
27.30 \pm 5.5^{* * *} \\
\end{array}$ & $\begin{array}{l}75 \\
74 \\
67 \\
69 \\
69 \\
82\end{array}$ & $\begin{array}{l}22 \\
19 \\
30 \\
27 \\
23 \\
15\end{array}$ & $\begin{array}{l}2 \\
7 \\
3 \\
4 \\
7 \\
3\end{array}$ & $\begin{array}{l}1 \\
0 \\
0 \\
0 \\
1 \\
0\end{array}$ & $\begin{array}{r}29 \\
33 \\
36 \\
35 \\
40 \\
21 \\
32.3 \pm 6.6 * * * \\
\end{array}$ \\
\hline $\begin{array}{l}\text { Cyclophosphamide } \\
(50 \mathrm{mg} / \mathrm{kg})\end{array}$ & $\begin{array}{c}\mathrm{F}_{1} \\
\mathrm{~F}_{2} \\
\mathrm{~F}_{3}^{3} \\
\mathrm{M}_{1} \\
\mathrm{M}_{2} \\
\mathrm{M}_{3} \mathrm{SD} \\
\text { Mean } \pm \text { SD }\end{array}$ & $\begin{array}{c}40 \\
38 \\
37 \\
27 \\
32 \\
49 \\
37.10 \pm 7.4 * * * \\
\end{array}$ & $\begin{array}{l}60 \\
62 \\
63 \\
73 \\
68 \\
51\end{array}$ & $\begin{array}{l}21 \\
25 \\
17 \\
17 \\
17 \\
28\end{array}$ & $\begin{array}{r}13 \\
9 \\
15 \\
7 \\
11 \\
13\end{array}$ & $\begin{array}{l}6 \\
4 \\
5 \\
3 \\
4 \\
8\end{array}$ & $\begin{array}{c}65 \\
55 \\
62 \\
40 \\
51 \\
78 \\
58.5 \pm 13.0^{* * *} \\
\end{array}$ \\
\hline
\end{tabular}

*Significantly different from the negative control $(\mathrm{P}<0.05)$. **Significantly different from the negative control $(\mathrm{P}<$ $0.01)$. ${ }^{* * *}$ Significantly different from the negative control $(\mathrm{P}<0.001) .{ }^{1}$ Total number of damaged cells $($ classes $1+2+3)$.

Table 3. Polychromatic erythrocytes with micronuclei (MNPCE) observed in bone marrow cells of female (F) and male (M) Swiss mice and Wistar rats treated with Rosmarinus officinalis essential oil, and respective controls.

\begin{tabular}{|c|c|c|c|c|c|c|c|c|c|}
\hline \multirow[t]{2}{*}{ Treatments and animal specie } & \multirow{2}{*}{$\begin{array}{c}\text { Dose } \\
(\mathrm{mg} / \mathrm{kg})\end{array}$} & \multicolumn{6}{|c|}{ Number of MNPCE per animal } & \multirow{2}{*}{$\begin{array}{c}\text { MNPCE } \\
(\text { Mean } \pm \text { SD) }\end{array}$} & \multirow{2}{*}{$\begin{array}{c}\mathrm{PCE} / \mathrm{NCE} \\
(\mathrm{Mean} \pm \mathrm{SD})\end{array}$} \\
\hline & & $\mathrm{F}_{1}$ & $\mathrm{~F}_{2}$ & $\mathrm{~F}_{3}$ & $\mathrm{M}_{1}$ & $\mathrm{M}_{2}$ & $\mathrm{M}_{3}$ & & \\
\hline Negative control & 0 & & & & & & & & \\
\hline Swiss mice & & 1 & 2 & 1 & 0 & 2 & 1 & $1.1 \pm 0.75$ & $1.72 \pm 0.37$ \\
\hline Wistar rat & & 1 & 2 & 2 & 2 & 3 & 2 & $2.0 \pm 0.63$ & \\
\hline R. officinalis oil & 300 & & & & & & & & \\
\hline Swiss mice & & 2 & 1 & 2 & 3 & 3 & 2 & $2.1 \pm 0.75$ & $1.25 \pm 0.32$ \\
\hline Wistar rat & & 3 & 0 & 5 & 0 & 5 & 8 & $3.5 \pm 3.14$ & \\
\hline R. officinalis oil & 1000 & & & & & & & & \\
\hline Swiss mice & & 2 & 3 & 3 & 2 & 2 & 3 & $2.5 \pm 0.54 *$ & $1.69 \pm 0.53$ \\
\hline Wistar rat & & 4 & 7 & 1 & 4 & 5 & 6 & $4.5 \pm 2.07$ & \\
\hline R. officinalis oil & 2000 & & & & & & & & \\
\hline Swiss mice & & 3 & 4 & 3 & 3 & 3 & 2 & $3.0 \pm 0.63 * *$ & $1.64 \pm 0.37$ \\
\hline Wistar rat & & 6 & 6 & 10 & 5 & 8 & 9 & $7.3 \pm 1.96^{* *}$ & \\
\hline Cyclophosphamide & 50 & & & & & & & & \\
\hline Swiss mice & & 6 & 8 & 5 & 7 & 6 & 7 & $6.5 \pm 1.04 * * *$ & $1.61 \pm 0.55$ \\
\hline Wistar rat & & 7 & 9 & 10 & 12 & 11 & 11 & $10.0 \pm 1.78^{* * *}$ & \\
\hline
\end{tabular}

Two thousand cells were analyzed per animal, for a total of 12,000 cells per group. * Significantly different from negative control $(\mathrm{P}<0.05)$. ${ }^{* *}$ Significantly different from negative control $(\mathrm{P}<0.01)$. ***Significantly different from negative control $(\mathrm{P}<0.001) . \mathrm{PCE} / \mathrm{NCE}=$ poly- and normochromatic erythrocytes. 
In the micronucleus assay evaluation of the mutagenic potential of rosemary oil (Table 3 ), there was a significant increase in the mean number of micronucleated polychromatic erythrocytes in bone marrow with $1000 \mathrm{mg}$ oil $/ \mathrm{kg}$ in Swiss mice $(\mathrm{P}<0.05)$ and $2000 \mathrm{mg}$ oil $/ \mathrm{kg}$ in both mice and rats $(\mathrm{P}<0.01)$, as well as in the positive control.

The ratio of polychromatic erythrocytes to normochromatic erythrocytes (Table 3) analyzed in Swiss mice bone marrow cells treated with cyclophosphamide or oil was not significantly different from the negative control group $(\mathrm{P}>0.05)$.

A single exposure to rat of three doses of the oil significantly increased the mean number of chromosome aberrations at metaphase at $2000 \mathrm{mg} / \mathrm{kg}$ (Table 4). As expected, animals treated with cyclophosphamide had a significantly higher number of chromosome aberrations. In all treatments with essential oil, the most frequent chromosomal aberrations observed were gaps, followed by chromatid breaks, isochromatidic breaks and deletions. In the oil-treated groups, cells with more than one chromosome aberration were not observed. The mitotic index (used as a measure of evaluation of cell cycle kinetics) values obtained from the analysis of 1000

\begin{tabular}{|c|c|c|c|c|c|c|c|c|c|}
\hline \multirow[t]{3}{*}{ Treatments } & \multirow[t]{3}{*}{ Animal } & \multirow[t]{3}{*}{ MI (\%) } & \multicolumn{5}{|c|}{ Chromosomal aberrations } & \multirow{3}{*}{$\begin{array}{c}\text { Total CA } \\
\text { without gaps }\end{array}$} & \multirow{3}{*}{$\begin{array}{c}\text { Cells } \\
\text { with CA }\end{array}$} \\
\hline & & & \multicolumn{2}{|c|}{ Gaps } & \multicolumn{3}{|c|}{ Breaks } & & \\
\hline & & & $\mathrm{C}$ & IC & $\mathrm{C}$ & $\mathrm{IC}$ & $\mathrm{AO}$ & & \\
\hline $\begin{array}{l}\text { Negative control } \\
\text { (Water) }\end{array}$ & $\begin{array}{c}\mathrm{F}_{1} \\
\mathrm{~F}_{2} \\
\mathrm{~F}_{3} \\
\mathrm{M}_{1} \\
\mathrm{M}_{2} \\
\mathrm{M}_{3} \\
\mathrm{Mean} \pm \mathrm{SD}\end{array}$ & $\begin{array}{c}5.1 \\
6.4 \\
8.9 \\
7.9 \\
5.8 \\
7.2 \\
6.8 \pm 1.3\end{array}$ & $\begin{array}{l}1 \\
0 \\
1 \\
1 \\
1 \\
0\end{array}$ & $\begin{array}{l}0 \\
0 \\
0 \\
0 \\
0 \\
0\end{array}$ & \begin{tabular}{l|l} 
& \\
1 & \\
1 \\
1 \\
1 \\
0
\end{tabular} & $\begin{array}{l}0 \\
0 \\
0 \\
0 \\
0 \\
0\end{array}$ & $\begin{array}{c}0 \\
0 \\
0 \\
0 \\
0 \\
1 \text { del }\end{array}$ & $\begin{array}{c}1 \\
1 \\
1 \\
1 \\
1 \\
1 \\
1.0 \pm 0.0\end{array}$ & $\begin{array}{l}1 \\
1 \\
1 \\
1 \\
1 \\
1\end{array}$ \\
\hline $\begin{array}{l}\text { R. officinalis oil } \\
(300 \mathrm{mg} / \mathrm{kg})\end{array}$ & $\begin{array}{c}\mathrm{F}_{1} \\
\mathrm{~F}_{2} \\
\mathrm{~F}_{3} \\
\mathrm{M}_{1} \\
\mathrm{M}_{2} \\
\mathrm{M}_{3} \\
\mathrm{Mean} \pm \mathrm{SD}\end{array}$ & $\begin{array}{c}11.4 \\
7.7 \\
12.9 \\
12.3 \\
12.7 \\
8.9 \\
10.9 \pm 2.1 *\end{array}$ & $\begin{array}{l}1 \\
2 \\
1 \\
0 \\
1 \\
2\end{array}$ & $\begin{array}{l}0 \\
0 \\
1 \\
1 \\
2 \\
1\end{array}$ & $\begin{array}{l}2 \\
0 \\
3 \\
0 \\
0 \\
1\end{array}$ & $\begin{array}{l}0 \\
1 \\
0 \\
0 \\
0 \\
0\end{array}$ & $\begin{array}{c}0 \\
0 \\
0 \\
0 \\
2 \mathrm{r} \\
0\end{array}$ & $\begin{array}{c}2 \\
1 \\
3 \\
0 \\
2 \\
1 \\
1.5 \pm 1.0\end{array}$ & $\begin{array}{l}2 \\
1 \\
3 \\
0 \\
2 \\
1\end{array}$ \\
\hline $\begin{array}{l}\text { R. officinalis oil } \\
(1000 \mathrm{mg} / \mathrm{kg})\end{array}$ & $\begin{array}{c}\mathrm{F}_{1} \\
\mathrm{~F}_{2} \\
\mathrm{~F}_{3} \\
\mathrm{M}_{1} \\
\mathrm{M}_{2} \\
\mathrm{M}_{3} \\
\text { Mean } \pm \mathrm{SD}\end{array}$ & $\begin{array}{c}12.1 \\
5.5 \\
5.9 \\
7.4 \\
9.9 \\
12.4 \\
8.8 \pm 3.0\end{array}$ & $\begin{array}{l}0 \\
4 \\
0 \\
0 \\
0 \\
1\end{array}$ & $\begin{array}{l}2 \\
0 \\
1 \\
0 \\
4 \\
4\end{array}$ & $\begin{array}{l}3 \\
0 \\
1 \\
2 \\
1 \\
1\end{array}$ & $\begin{array}{l}0 \\
1 \\
0 \\
0 \\
0 \\
1\end{array}$ & $\begin{array}{c}1 \mathrm{r} \\
0 \\
1 \mathrm{del} \\
0 \\
1 \mathrm{del} \\
0\end{array}$ & $\begin{array}{c}4 \\
1 \\
2 \\
2 \\
2 \\
2 \\
2.16 \pm 0.9\end{array}$ & $\begin{array}{l}4 \\
1 \\
2 \\
2 \\
2 \\
2\end{array}$ \\
\hline $\begin{array}{l}\text { R. officinalis oil } \\
(2000 \mathrm{mg} / \mathrm{kg})\end{array}$ & $\begin{array}{c}\mathrm{F}_{1} \\
\mathrm{~F}_{2} \\
\mathrm{~F}_{3} \\
\mathrm{M}_{1} \\
\mathrm{M}_{2} \\
\mathrm{M}_{3} \\
\text { Mean } \pm \mathrm{SD}\end{array}$ & $\begin{array}{c}6.5 \\
12.2 \\
7.8 \\
11.4 \\
11.8 \\
12.5 \\
10.3 \pm 2.5\end{array}$ & $\begin{array}{l}1 \\
0 \\
1 \\
1 \\
0 \\
2\end{array}$ & $\begin{array}{l}1 \\
2 \\
0 \\
5 \\
3 \\
2\end{array}$ & $\begin{array}{l}2 \\
2 \\
2 \\
1 \\
2 \\
2\end{array}$ & $\begin{array}{l}0 \\
1 \\
0 \\
0 \\
0 \\
0\end{array}$ & $\begin{array}{c}\text { 1f } \\
1 \mathrm{del} \\
1 \mathrm{f} \\
1 \mathrm{del} \\
1 \mathrm{r} \\
2 \mathrm{del}\end{array}$ & $\begin{array}{c}3 \\
4 \\
3 \\
2 \\
3 \\
4 \\
3.16 \pm 0.7^{*}\end{array}$ & $\begin{array}{l}3 \\
4 \\
3 \\
2 \\
3 \\
4\end{array}$ \\
\hline $\begin{array}{l}\text { Positive control } \\
\text { cyclophosphamide } \\
(50 \mathrm{mg} / \mathrm{kg})\end{array}$ & $\begin{array}{c}\mathrm{F}_{1} \\
\mathrm{~F}_{2} \\
\mathrm{~F}_{3} \\
\mathrm{M}_{1} \\
\mathrm{M}_{2} \\
\mathrm{M}_{3} \mathrm{SD} \\
\text { Mean } \pm \text { SD }\end{array}$ & $\begin{array}{c}7.2 \\
8.5 \\
7.8 \\
8.7 \\
7.5 \\
7.4 \\
7.8 \pm 0.6\end{array}$ & $\begin{array}{l}3 \\
4 \\
3 \\
3 \\
3 \\
5\end{array}$ & $\begin{array}{l}0 \\
1 \\
3 \\
1 \\
3 \\
3\end{array}$ & $\begin{array}{l}3 \\
2 \\
2 \\
2 \\
2 \\
3\end{array}$ & $\begin{array}{l}0 \\
0 \\
1 \\
0 \\
0 \\
0\end{array}$ & $\begin{array}{c}1 \mathrm{del} \\
2 \mathrm{del}, 1 \mathrm{f} \\
1 \mathrm{r} \\
3 \mathrm{del} \\
1 \mathrm{del}, 1 \mathrm{f} \\
1 \mathrm{del} / 1 \mathrm{r}\end{array}$ & $\begin{array}{c}4 \\
5 \\
4 \\
5 \\
4 \\
5 \\
4.5 \pm 0.5^{*}\end{array}$ & $\begin{array}{l}4 \\
5 \\
4 \\
5 \\
4 \\
5\end{array}$ \\
\hline
\end{tabular}

One hundred cells were analyzed per animal, for a total of 600 cells per treatment. $\mathrm{C}=$ chromatidtype; $\mathrm{IC}=$ isochromatid-type; $\mathrm{OA}=$ other aberrations: $d e l=$ deletion; $\mathrm{f}=$ acentric fragment; $\mathrm{r}=\mathrm{ring}$; *Significantly different from negative control $(\mathrm{P}<0.001)$. 
cells/animal for a sample of 30 animals ( $\mathrm{N}=6$ /group) ranged from 5.1 to $12.9 \%$ (means). The mitotic index of bone marrow cells exposed to rosemary oil increased only at the $300 \mathrm{mg} / \mathrm{kg}$ dose, when compared to the negative control.

\section{DISCUSSION}

We assessed the genotoxicity/mutagenicity of $R$. officinalis essential oil in rodent peripheral blood leukocytes and in liver and bone marrow cells. The choice of these cells is mainly because of the large number of easily available mitotic cells and the thick network of blood vessels, which allows good contact of the target cells with the adsorbed or administered compound (Barale et al., 1992). Rosemary oil induced a significant increase in DNA migration of the liver and leukocyte cells at all three doses in the comet assay, and at the highest dose $(2000 \mathrm{mg} / \mathrm{kg})$ it significantly increased the number of micronucleated cells and chromosome aberrations in bone marrow cells, based on the micronucleus and chromosome aberration assays. In this latter assay, although the number of gaps at all three doses of the oil was increased when compared with the control group, gaps were excluded from the statistical analysis since they are considered by some investigators to be of debatable genetic significance, because their presence does not always lead to chromosome aberrations in the subsequent cell divisions (Preston et al., 1987).

A decrease in the ratio of polychromatic erythrocytes to normochromatic erythrocytes in the micronucleus test and a decreased mitotic index in the chromosome aberration assay are indicators of bone marrow toxicity induced by mutagens (Suzuki et al., 1989). Although rosemary oil increased DNA damage in liver and leukocyte cells, and chromosome aberrations, at the $2000 \mathrm{mg} / \mathrm{kg}$ dose, the results of polychromatic to normochromatic erythrocyte ratio and mitotic index assay showed that a single dose of rosemary oil did not negatively affect hematopoiesis.

Gaiani et al. (2006) investigated the genotoxic potential of hydro-alcoholic extract of $R$. officinalis in vivo in bone marrow cells of Wistar rats by micronucleus and chromosome aberration assays and concluded that at $6.43,100$ and $200 \mathrm{mg} / \mathrm{kg}$ body weight doses, this extract is not mutagenic. We used higher doses of rosemary oil, the smallest dose tested $(300 \mathrm{mg} / \mathrm{kg})$ was chosen on the basis of $\mathrm{ED}_{50}$ of $261 \mathrm{mg} / \mathrm{kg}$, obtained by Faria (2005) in an anti-inflammatory and analgesic investigation.

There are other reports of toxic effects of rosemary oil. Papachristos and Stamopoulos (2002) reported fumigant toxicity of rosemary essential oil vapors against larvae and pupae of Acanthoscelides obtectus; ovocidal, repellent and fumigant activity against other insects was also reported (Shaaya et al., 1997; Hori, 1998; Tunç et al., 2000). Damasco and Lemonica (1999) reported a high incidence of anomalous embryos in rats treated with $260 \mathrm{mg} / \mathrm{kg}$ rosemary ethanolic extract from the first to the fourth day of gestation. A higher dose $(1040 \mathrm{mg} /$ $\mathrm{kg}$ ) administered during the same period reduced the number of blastocysts found in the uterus. The genotoxic and mutagenic effects of the rosemary oil that we observed here could be responsible for the embryotoxic effects reported in the above studies, since chromosome breaks and deletions are important factors responsible for abortion in humans and animals (Beckman and Brent, 1984).

We concluded that rosemary oil induces genotoxicity in peripheral blood and liver cells of mice, and induces on the composition of the oil, which can vary depending on the geographic origin of this material. 


\section{ACKNOWLEDGMENTS}

We thank the Brazilian agencies CNPq (\#306544/2006-7), FAPESP (\#2006/57514-2) and FAPEMIG (Rede Mineira de Ensaios Toxicológicos e Farmacológicos de Produtos Terapêuticos, EDT \#1879/02) for financial support and Patrícia C. Martins for technical assistance.

\section{REFERENCES}

al-Sereiti MR, Abu-Amer KM and Sen P (1999). Pharmacology of rosemary (Rosmarinus officinalis Linn.) and its therapeutic potentials. Indian J. Exp. Biol. 37: 124-130.

Aqel MB (1991). Relaxant effect of the volatile oil of Rosmarinus officinalis on tracheal smooth muscle. J. Ethnopharmacol. 33: 57-62.

Barale R, Scapoli C, Falezza A, Ventura L, et al. (1992). Skin cytogenetic assay for the detection of clastogens-carcinogens topically administered to mice. Mutat. Res. 271: 223-230.

Baratta MT, Dorman HJD, Deans SG, Biondi DM, et al. (1998). Chemical composition, antimicrobial and antioxidative activity of laurel, sage, rosemary, oregano and coriander essential oils. J. Essent. Oil Res. 10: 618-627.

Beckman DA and Brent RL (1984). Mechanisms of teratogenesis. Annu. Rev. Pharmacol. Toxicol. 24: 483-500.

Burkhard PR, Burkhardt K, Haenggeli CA and Landis T (1999). Plant-induced seizures: reappearance of an old problem. J. Neurol. 246: 667-670.

Collins MA and Charles HP (1987). Antimicrobial activity of carnosol and ursolic acid: two anti-oxidant constituents of Rosmarinus officinalis L. Food Microbiol. 4: 311-315.

Damasco DC and Lemonica IP (1999). Embryotoxicity and antiimplantation effects of rosemary (Rosmarinus officinalis L.) extract in pregnant rats within preimplantation period. Rev. Bras. Toxicol. 12: 47-54.

Faria LRD (2005). Pharmacological Validation of the Essential Oil from Rosmarinus officinalis L. (rosemary) - Antiinflammatory and Analgesic Activities. Master's thesis, UNIFENAS, Alfenas.

Gaiani TF, Carvalho JCT, Silva JMSF and Maistro EL (2006). Absence of clastogenic effects of the extract from medicinal plant Rosmarinus officinalis L. on Wistar rat bone marrow cells. Cytologia 71: 101-106.

Gollapudi BB and McFadden LG (1995). Sample size for the estimation of polychromatic to normochromatic erythrocyte ratio in the bone marrow micronucleus test. Mutat. Res. 347: 97-99.

Hartmann A and Speit G (1997). The contribution of cytotoxicity to DNA-effects in the single cell gel test (comet assay). Toxicol. Lett. 90: 183-188.

Héthelyi E, Kaposi P, Domonkos J and Kernoczi Z (1987). GC/MS investigation of the essential oils Rosmarinus officinalis L. Acta Pharm. Hung. 57: 159-169.

Hori M (1998). Repellency of rosemary oil against Myzus persicae in a laboratory and in a screenhouser. J. Chem. Ecol. 24: $1425-1432$.

Klaude M, Eriksson S, Nygren J and Ahnstrom G (1996). The comet assay: mechanisms and technical considerations. Mutat. Res. 363: 89-96.

Krishna G and Hayashi M (2000). In vivo rodent micronucleus assay: protocol, conduct and data interpretation. Mutat. Res. 455: 155-166.

Larràn S, Ringuelet JA, Carranza MR, Henning CP, et al. (2001). In vitro fungistatic effect of essential oils against Ascosphaera apis. J. Essent. Oil Res. 13: 122-124.

Lemonica IP, Damasceno DC and di-Stasi LC (1996). Study of the embryotoxic effects of an extract of rosemary (Rosmarinus officinalis L.). Braz. J. Med. Biol. Res. 29: 223-227.

Mangena T and Muyima NY (1999). Comparative evaluation of the antimicrobial activities of essential oils of Artemisia afra, Pteronia incana and Rosmarinus officinalis on selected bacteria and yeast strains. Lett. Appl. Microbiol. 28: 291-296.

Newall CA, Anderson L and Phillipson J (1996). Herbal Medicines - A Guide for Health Care Professionals. The Pharmaceutical Press, London.

Papachristos DP and Stamopoulos DC (2002). Toxicity of vapours of three essential oils to the immature stages of Acanthoscelides obtectus (Say) (Coleoptera: Bruchidae). J. Stor. Prod. Res. 38: 365-373.

Preston RJ, Dean BJ, Galloway S, Holden H, et al. (1987). Mammalian in vivo cytogenetic assays. Analysis of chromosome aberrations in bone marrow cells. Mutat. Res. 189: 157-165.

Savage JR (1976). Classification and relationships of induced chromosomal structural changes. J. Med. Genet. 13: 103-122. Schmid W (1975). The micronucleus test. Mutat. Res. 31: 9-15. 
Shaaya E, Kostjukovski M, Eilberg J and Sukprakarn C (1997). Plant oils as fumigants and contact insecticides for the control of stored-product insects. J. Stor. Prod. Res. 33: 7-15.

Singh NP, McCoy MT, Tice RR and Schneider EL (1988). A simple technique for quantitation of low levels of DNA damage in individual cells. Exp. Cell Res. 175: 184-191.

Sokal RR and Rohlf FJ (1995). The Principles and Practice of Statistics in Biology Research. In: Biometry (Freeman WH, ed.). San Francisco, 175-205, 404-486.

Speit G and Hartmann A (1999). The Comet Assay (Single-cell Gel Test). In: Methods in Molecular Biology. Vol. 113. DNA Repair Protocols: Eukaryotic Systems (Henderson DS, ed.). Humana Press Inc., Totowa, 203-212.

Suzuki Y, Nagae Y, Li J, Sakaba H, et al. (1989). The micronucleus test and erythropoiesis. Effects of erythropoietin and a mutagen on the ratio of polychromatic to normochromatic erythrocytes ( $\mathrm{P} / \mathrm{N}$ ratio). Mutagenesis 4: 420-424.

Tunç I, Berger BM, Erler F and Dagli F (2000). Ovicidal activity of essential oils from five plants against two storedproduct insects. J. Stor. Prod. Res. 36: 161-168. 